\title{
Industrial Engineering for Healthcare Management - Example Lean Management and ICT Tools
}

\author{
Aleksander Buczacki ${ }^{1}$, Bartłomiej Gładysz ${ }^{1}$, Dariusz Timler ${ }^{2}$ \\ 1 Faculty of Production Engineering, Warsaw University of Technology, Poland \\ 2 Department of Emergency Medicine and Disaster Medicine, Medical University of Lodz, \\ Poland
}

\begin{abstract}
Industrial engineering is a field dealing with optimization of complex processes, systems, or organizations by developing, improving and implementing integrated systems of people, money, knowledge, information, equipment, energy, and materials. Hence, the scope of industrial engineering is wide and includes various fields, from manufacturing, through banking, different types of services, to administration and healthcare. Various industrial engineering tools could be implemented in healthcare settings. The use of such tools is popular in western economies. For example, simulation modelling of services is popular in the US. However, there is still a very limited number of case studies on the application of such tools in healthcare that would consider the Polish economy. The aim of this paper is to present selected successful applications of lean management tools in the Polish healthcare. This may serve as an inspiration for healthcare organizations to search for and implement methodological approaches to improve their services.
\end{abstract}

\section{Introduction}

Medicine is a dynamically developing field. It can be observed, however, that the organization of healthcare in hospitals and clinics still has a significant scope for improvement. This means that the potential of development of medicine is not yet fully exploited and constrained by the limitations of healthcare organization.

Healthcare is a very dynamically growing sector of economy and the labor market. The general health condition of society is very important for the growth of economy and if neglected, it generates significant costs for the national economy (Serwis Rzeczypospolitej Polskiej, 2015).

Polish healthcare is assessed rather poorly using Euro Health Consumer Index, i.e. 585 out of 1000 possible points, which places Poland at the fourth 
position from the bottom in the ranking. Worse results were achieved only by Albania, Romania, and Hungary. The EHCI value is increasing very slowly (511 in 2014, 523 in 2015, 564 in 2016, 584 in 2017) (Björnberg \& Phang, 2019).

Industrial engineering offers a variety of methods and tools that could be implemented in order to improve healthcare, specifically if considering such functions as organization, planning, directing (leading), controlling, and motivation. Literature distinguishes two types of mentality, i.e. managerial and clinical. The latter is usually in opposition to organizational improvements in healthcare. Such issues have been noticed at governmental levels, which resulted in top-down and country-wise computerization of the Polish healthcare. Implementations of Healthcare Information Systems and their integration with governmental databases are factors important for smooth operation of healthcare units. These are however, insufficient nowadays. Management sciences and industrial engineering offer some interesting approaches for organizational improvements in their toolbox, e.g. lean management focused on the elimination of waste (Jap. muda). Waste results in irregularities (Jap. mura) and less than optimal allocation of resources (Jap. muri) (Imai, 2012). Lean management evolved from the Toyota Production System. There are also numerous information and communication technologies that can be applied in healthcare for organizational improvements, e.g. simulation modelling and autoidentification.

The aim of this paper is to present a subjective review and excerpts from the lean management and ICT toolbox, leading to an analysis of their possible applications in healthcare settings. A case study is presented to show applications of lean management tools in a hospital emergency department (ED). Specifically, 5S, Value Stream Mapping, and standardization are discussed for the chosen ED in order to show how to identify problems and plan improvements methodologically. It is also indicated that other complementary tools for the chosen ED may be implemented. The case study in question may constitute a certain benchmark for other EDs, with 235 public EDs in Poland (Serwis Rzeczypospolitej Polskiej, 2019).

\section{Lean Healthcare}

Lean management originated from the lean manufacturing concept, which focuses on the identification and elimination of waste occurring in production processes. The author and designer of the Toyota Production 
System defined 7 types of waste, i.e. transportation, inventory, motion, waiting, overproduction, over-processing, and defects (Ohno, 1998). It should be stressed that the same types of waste can be observed not only in production processes, but in other areas as well, e.g. administration, healthcare, and services in general.

In practice, a specific waste usually influences other types of waste. Waste elimination should be planned considering their influence on all other types of waste. For example, over-production usually generates inventory and other types of waste in succeeding operations. All lean methods and techniques focus on the aforementioned identification and elimination of waste. Later publications put the emphasis on people (Liker, 2004).

The lean concept was introduced by MIT researchers, who analyzed, among others, the sources of Japanese car-makers' competitive advantage over American ones (Krafcik, 1998; Womack \& Jones, 1996; Womack et al., 1990). They described the following five general lean rules, i.e. 1) value, 2) value stream, 3) flow, 4) pull, 5) perfection.

All activities should be focused on the creation of value as defined by the customer (could be an internal one). Activities such as value-adding, necessary but non-value-adding, and non-value-adding (waste) could be observed in manufacturing processes. All processes should be mapped and analyzed in the context of the delivered value, i.e. non-value-adding operations should be eliminated, stoppages and backflows should be eliminated, and the process should be executed perfectly and in accordance with the customer's takt time (in a Just-in-Time manner). Problems should be solved immediately. The lean toolbox can be divided into 3 categories (Gladysz \& Buczacki, 2018):

- identification and analysis of waste, e.g. causal diagrams, Value Stream Mapping (VSM),

- implementation of improvements, e.g. Single Minute Exchange of Die (SMED), poka-yoke,

- process monitoring, e.g. andon, supermarket.

One method or tool may have different purposes and they are not necessarily typical for the lean concept only. Usually they are also utilized in other approaches focused on process improvement.

Lean management as a concept implemented in healthcare is labeled as "lean healthcare" (Kovacevic et al., 2016) or "lean hospitals" (Graban, 2011). Jimmerson (2017) considered the seven mudas for healthcare and listed: 1) Confusion, 2) Motion/conveyance, 3) Waiting, 4) Overprocessing, 5) Inventory, 6) Defects, 7) Overproduction. The first application of lean healthcare was reported in 2000 in the UK, followed by 2002 in 


\section{Aleksander Buczacki et al.}

the USA and today it is accepted globally (Radnor et al., 2012). There is evidence of its positive impacts on healthcare organization, e.g.:

- reduction of average waiting time for the first visit from 23 to 12 days and of lead time by $48 \%$ in Scotland Cancer Center,

- reduction of time taken to process important categories of blood from 2 days to 2 hours, reduction of average turnaround time in pathology from over 24 hours to 2-3 hours in Royal Bolton Hospital,

- reduced staff walking distance, reduced lab space and specimen processing turnaround time by $20 \%$, reduced manpower and their transfer to other critical points, decreased numbers of days of average patient's stay from 6.29 to 5.72 days in Nebraska Medical Center,

- intensive care unit cost-reduction of almost 0.5 mln USD per year, $90 \%$ reduction in number of recorded infections after 90 days of implementation of changed procedure for intravenous line insertion in Pittsbugh General Hospital.

On the contrary, there are substantial barriers for organizational innovations, exemplified by lean healthcare. They are rooted in the well-known concept of clinical mentality (Freidson, 1972). Although this is not a new phenomenon, the concept is still valid nowadays. Clinical mentality is appropriate and required in medical procedures. However, it limits organizational improvements. The reasons lie in the different viewpoints of medical and managerial staff in terms of:

- execution of processes (patient-wise vs. organization-wise),

- responsibility (personal vs. organizational),

- organizational dependencies (horizontal/collegial vs. vertical/hierarchical),

- timeframe (short-term vs. long-term),

- feedback (immediate/concrete vs. delayed/fuzzy),

- tolerance for ambiguity (low vs. high).

Both mentalities (managerial and clinical) seem to be fully contrary. However, both are necessary for effective and efficient performance of healthcare units in their different aspects. Managers obviously need to understand the medical priorities of medical staff. On the other hand, medical staff should be open for organizational improvements, which would lead to better quality of healthcare processes.

Systematic literature review of lean healthcare has been presented and included 101 papers from the period 2000-2016 (Antony et al., 2019). The scope of this analysis proves that there are many reports on lean implementations in healthcare, and those papers answer questions concerning their drivers, limitations, motivations, or benefits. The discussed review, however, 
synthesized the knowledge based on US (29), UK (23), and Swedish (13) applications. There had been no paper related to Poland. Therefore, the general question was raised, i.e. whether lean healthcare was applied in Poland. And if it was, then whether this should be disseminated and presented as a potential benchmark for other healthcare units. This goal was challenged by the identification of an exemplary lean healthcare application in Poland and a discussion of such a case study.

Implementation of the lean approach in the Polish healthcare system is still in its emerging phase. There are some initiatives focused on the development of some tools dedicated to Polish hospitals, e.g. The LeanOZ project conducted by the Polish Society on Healthcare Economics. The results of the project were disseminated during a conference. Although it seems to be an important effort, it is not enough to fully disseminate knowledge about the lean approach among Polish healthcare institutions. Therefore, the aim of this paper is to start a discussion concerning lean healthcare in Poland through journal channels of communication and knowledge dissemination.

\section{Information and Communication Technologies for Healthcare}

Modern organization needs symbiosis and synergy both from organizational improvement based on methodological approaches (such as lean management) and ICT, which has become necessary to deliver goods and services. Such is also the case with healthcare services.

Hospital Information Systems are the part of informatics in healthcare settings that is mainly focused on administrative issues related to the delivered services. Therefore, one may find them also labeled as hospital management systems/software. These systems are built from different modules allowing better patient information management. Example modules include, but are not limited to, registration features and repository of laboratory analyses (e.g. imaging, blood, etc.).

A feature widely employed in such systems are barcodes used for patient identification in hospitals, but also for inventory (assets) management. Although barcodes are in their mature stage, there are also other autoidentification technologies, which can be used in hospitals. Such technologies are real time locating systems (RTLS) based on active radio frequency identification (RFID) (often based on standard Wi-Fi infrastructure, but proprietary radio standards also exist). RTLS is used for real time asset and staff management. Assets equipped with an RTLS tag are located on air 


\section{Aleksander Buczacki et al.}

and their location is accessible via software for anyone concerned. A good example may be infusion pumps, whose number is lower than the number of departments using them. Knowing the location and status of pumps in a hospital, it is possible to order the closest available one, saving time and costs. It is also possible to call the closest available medical worker with the necessary skills in case of an urgent situation - in this case RTLS tags serve as staff's personal badges. These tags, distributed to patients (e.g. in a form of bracelet), may also be equipped with panic buttons or movement and drop sensors, which enable them to send an alarm when an unexpected event occurs (e.g. patient's fall).

Another application of RFID (in this case passive) technology is tagging of surgical tools. Each tool equipped with a unique RFID tag is identified at each step, e.g. entering/leaving the operating room, or entering/leaving the autoclave for sterilization.

Simulation modeling is the tool that is widely used in industrial engineering, especially in manufacturing and logistics settings. However, simulation models may also be designed for healthcare setting, e.g. to simulate dispersion of hospital acquired infections, or the flow of patients through specific processes (e.g. to simulate the necessary capabilities of imaging laboratories), etc.

\section{Application of selected IE tools in Polish Emergency Department}

According to the national regulation in Poland, hospital emergency department (ED) may be formed in a hospital, which has:

- a surgical department with traumatology (and pediatric surgery in the case of children's healthcare),

- an anesthesiology and intensive care department,

- a diagnostic imaging laboratory.

ED must be enabled with $24 / 7$ access to:

- services delivered by the medical diagnostic laboratory,

- computed tomography, endoscopic examinations, including gastroscopy, rectoscopy, bronchoscopy, laryngoscopy,

- equipment for examinations at the patient's bed (critical parameters analyzer, bedside x-ray set, and mobile ultrasound scanner).

ED must also have access to $24 / 7$ airport or airstrip in close proximity (no need for specialized transportation to the ED, transportation no longer than 5 min.). Additionally, ED must employ at least head of the department (the doctor in charge of the department), a ward nurse, doctors in 
the number necessary for the proper functioning of the ward (at least two doctors who are simultaneously in the ED), and nurses or paramedics in the number necessary for the proper functioning of the ward (Rozporzadzenie Ministra Zdrowia z dnia 27 czerwca 2019 r. w sprawie szpitalnego oddziału ratunkowego, 2019).

The ED being considered in this article is the one within Copernicus Provincial Multidisciplinary Centre of Oncology and Traumatology in Lodz. The analyzed ED is a medium one as far as Polish conditions are concerned. It consists of the following Points of Services:

- 3 registration desks;

- Triage room;

- 3 assessment rooms (with beds);

- 2 tomography stations;

- Treatment room;

- 2 X-ray stations;

-2 resuscitation rooms;

-8 ED beds.

In the analysed ED, basic elements of lean have been implemented. The staff and management use the PDCA cycle for process improvement. As a basis, 5S was implemented as well as elements of visual management (Figure 1).
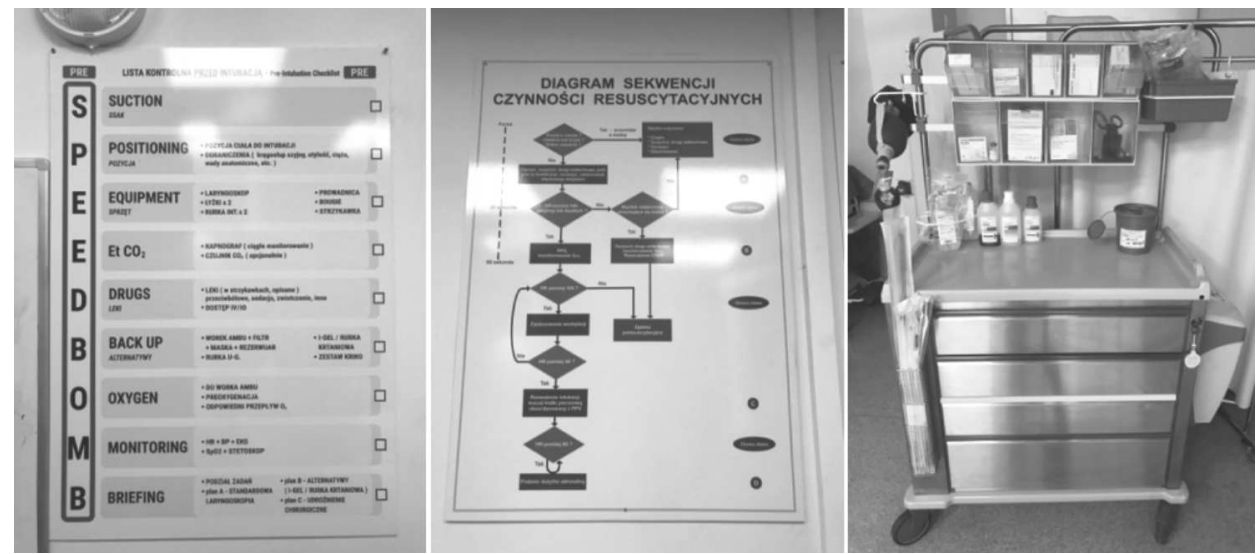

Figure 1. Examples of 5S, visual management and standardization - pre-intubation checklist (left), resuscitation procedure (center), organization of workstation (right)

In the ED, data about waste (classified in accordance with the lean approach) is collected and analysed. Value stream mapping in a healthcare setting is discussed in detail in (Jimmerson, 2017). 
The process at ED where time is of particularly importance for treatment is treatment of stroke patients. For this reason, this process was chosen for value stream mapping and the following aspects were analyzed: ED layout, alternative paths of the process, interviews with doctors, database of patients' treatments (year 2016), results of treatment based on discharges' records. Timestamps of the execution of the different steps of treatment were analyzed. The analysis considered a sample of 24,395 ED patients in 2016, including 577 stroke patients, with 104 cases of thrombolysis among them. Obviously, the presented results reflect the specific characteristics of the analyzed ED. Those results, however, may serve as a benchmark for a methodological approach to analyses and organizational improvements in healthcare.

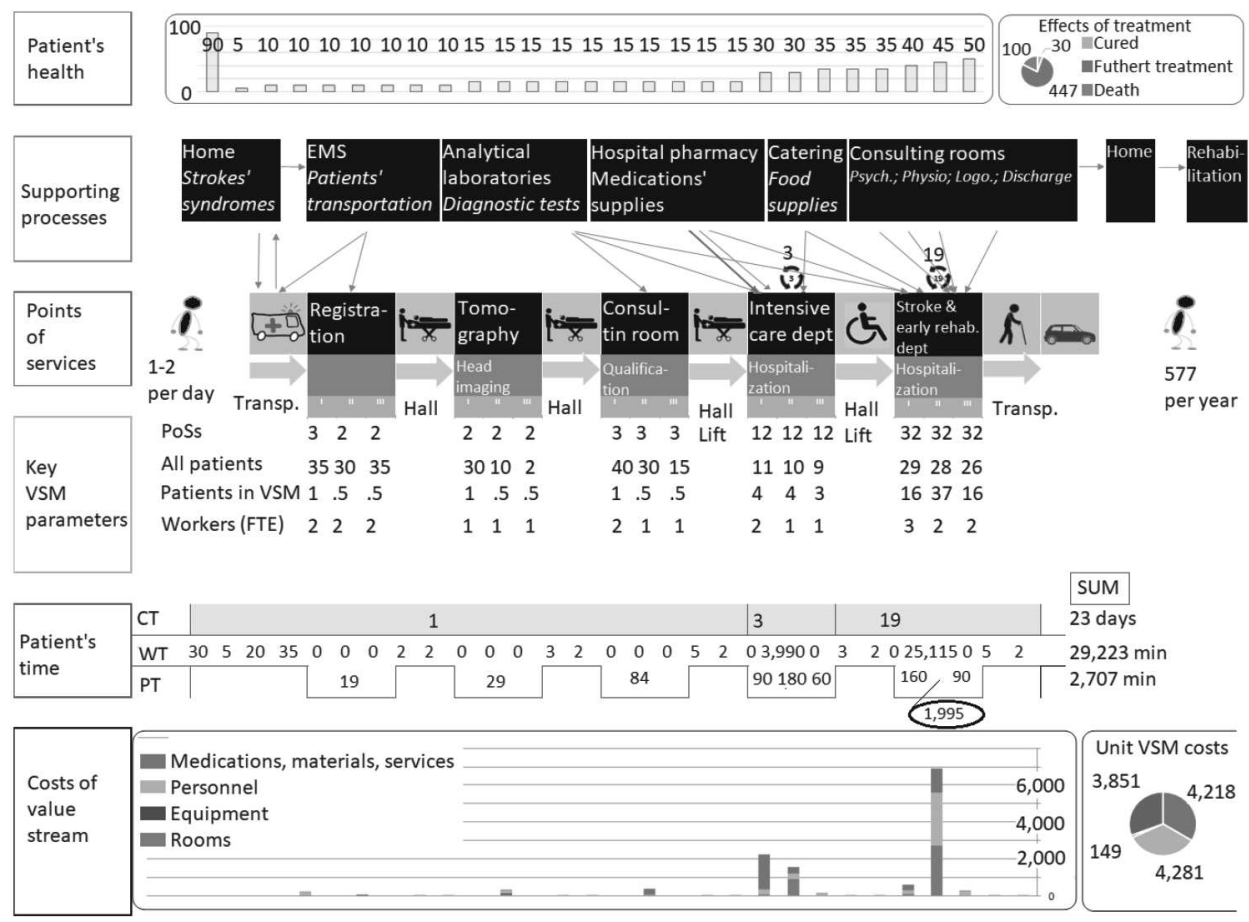

Figure 2. Current state VSM for stroke treatment in ED. Legend: CT - calendar time; WT - waiting or transportation time; PT - processing time

Current state VSM (Figure 2) presents the synthetic parameters and indicators depicting the analyzed process (Buczacki et al., 2017). It is constructed of six layers (swim lines), which are most important from the point 
of view of organization of treatment, considering the standards published by the Polish Society of Health Economics (Korkosz-Gębska \& Gębski, 2018, p. 19), i.e.:

- Health status - diagram based on standardized EQ-5D-5L survey questionnaire (scale $0-100$ points);

- Supporting processes and locations where services are delivered without the presence of patients;

- PoSs (Point of Services) - locations where medical services are delivered with the presence of patients;

- Key VSM parameters - depicting quantitative flow ratio of patients, including parameters of resources;

- Process time - divided into service/treatment time and waiting/transport time and calendar lead time (the sum of calendar days of treatment);

- Costs of value stream - operational costs for each stage of the process allocated to the costs of room's occupation, equipment exploitation, personnel, medicaments, materials, services related to patients.

The current state map was analysed, and a list of critical issues was created, i.e.:

- Critical indicator for stroke patients is stroke-to-thrombolysis time, which includes door-to-needle time in the ED;

- Critical internal indicator for stroke treatment is door-to-CT time;

- Critical success factor is communication between paramedics and ED staff;

- Critical success factor is the standardized procedure of thrombolysis with detailed work breakdown among ED personnel;

- Critical success factor is communication with doctors about the planned treatments.

- Critical success factor is communication between employees performing $\mathrm{CT}$ and those responsible for thrombolysis.

Current state VSM visualizes all phases of a patient's treatment. Patient can be described by two general states, i.e. in treatment (processed) or not in treatment. Processing time (PT) depicts the duration of value-adding activities. If a patient is not treated, then two sub-states are possible, i.e. waiting or transported. Both those sub-states are represented by the WT (time of non-value-adding activities) parameter on VSM. The WT/PT ratio was lower than $10 \%$, which is relatively low, and indicated the potential for organizational improvements. An analysis of current state VSM shows very high WT values for intensive care and stroke and early rehabilitation departments. Therefore, this is where improvement ac- 


\section{Aleksander Buczacki et al.}

tions should be implemented first of all. Based on the current state value stream map, the following actions/improvements were proposed as standards for doctors and ED staff and as a way to improve critical issues (listed above):

- Introduction of NIHSS (National Institute of Health Stroke Scale) survey;

- Implementation of checklists;

- Inclusion of a pharmacist in medical teams;

- Inclusion of a social official in the process of identification of witnesses of symptoms (possibly contact by phone, e-mail etc.);

- Implementation of PoCT (Point of Care Testing) for lab tests.

Several areas of necessary improvement actions, identified through value stream mapping, are listed in the "Application of selected IE tools in Polish Emergency Department" section. The proposed improvement actions are strictly related to standardisation of operations in the ED. It seems that a reduced door-to-needle is a rational result for the standardisation and design of detailed procedures (with responsibilities, assets listed, forms designed, etc.) for:

- Communication between paramedics and ED staff - questionnaire of data to be collected from paramedics by ED staff;

- Communication for doctors about schedules (leading to a decrease of patient waiting times);

- Communication between CT and thrombolysis performers leading to smooth flow between those locations, with reduced delays, waiting, and transport cycle times,

- Optimized and validated procedure for thrombolysis (leading to a decrease of thrombolysis cycle time);

Table 1. Triage scales

\begin{tabular}{|l|c|l|l|l|c|}
\hline \multicolumn{2}{|c|}{ Australian Triage Scale } & \multicolumn{2}{|c|}{$\begin{array}{c}\text { Canadian Triage and Acuity } \\
\text { Scale }\end{array}$} & \multicolumn{2}{|c|}{$\begin{array}{c}\text { Manchester Triage Scale } \\
\text { (Also in Poland) }\end{array}$} \\
\hline $\begin{array}{c}\text { Level/ } \\
\text { Description }\end{array}$ & $\begin{array}{c}\text { Waiting time } \\
\text { (up to) }\end{array}$ & $\begin{array}{c}\text { Level/ } \\
\text { Description }\end{array}$ & $\begin{array}{c}\text { Waiting time } \\
\text { (up to) }\end{array}$ & $\begin{array}{c}\text { Level/ } \\
\text { Description }\end{array}$ & $\begin{array}{c}\text { Waiting time } \\
\text { (up to) }\end{array}$ \\
\hline Resuscitation & $0 \mathrm{~min}$ & Resuscitation & $0 \mathrm{~min}$ & Red & Immediately \\
\hline Emergency & $10 \mathrm{~min}$ & Emergency & $15 \mathrm{~min}$ & Orange & $10 \mathrm{~min}$ \\
\hline Urgent & $30 \mathrm{~min}$ & Urgent & $30 \mathrm{~min}$ & Yellow & $60 \mathrm{~min}$ \\
\hline Semi-Urgent & $60 \mathrm{~min}$ & Less Urgent & $60 \mathrm{~min}$ & Green & $120 \mathrm{~min}$ \\
\hline Nonurgent & $120 \mathrm{~min}$ & Non Urgent & $120 \mathrm{~min}$ & Blue & $240 \mathrm{~min}$ \\
\hline
\end{tabular}


Since July 2019, Poland has applied one triage scale (Table 1) based on MTS (Manchester Triage Scale) (Rozporządzenie Ministra Zdrowia z dnia 27 czerwca 2019 r. w sprawie szpitalnego oddziału ratunkowego, 2019). A single standard simplifies hospital operations and enables comparative analyzes of all EDs in Poland. Previously, some EDs did not use any triage scale. Some used their own, but the majority of Polish EDs used MTS.

Emergency departments are appropriate units for the application of simulation modelling as the settings are fuzzy and of stochastic nature. Simulation is not yet implemented in the considered ED. However, practices and models were identified that could constitute a solid base for simulation modelling in the analyzed ED. The existing experiences with discrete-event simulation modelling applied for ED can be used as a starting point for simulation modelling of the specific case of the ED in question. Figure 3 and Figure 4 present a simplified model (Anylogic, 2019). Many authors, however, have developed more complex models dedicated to door-to-doctor (Ribeiro et al., 2016), overcrowding (Ahalt et al., 2018), impact of work pressure (Choi et al., 2019), and many others. Applying agent-based modelling for the analysed ED, one may design a model with three states of the agent (patient), i.e. 1) treated (processed), 2) waiting - not treated, 2) transported - not-treated.

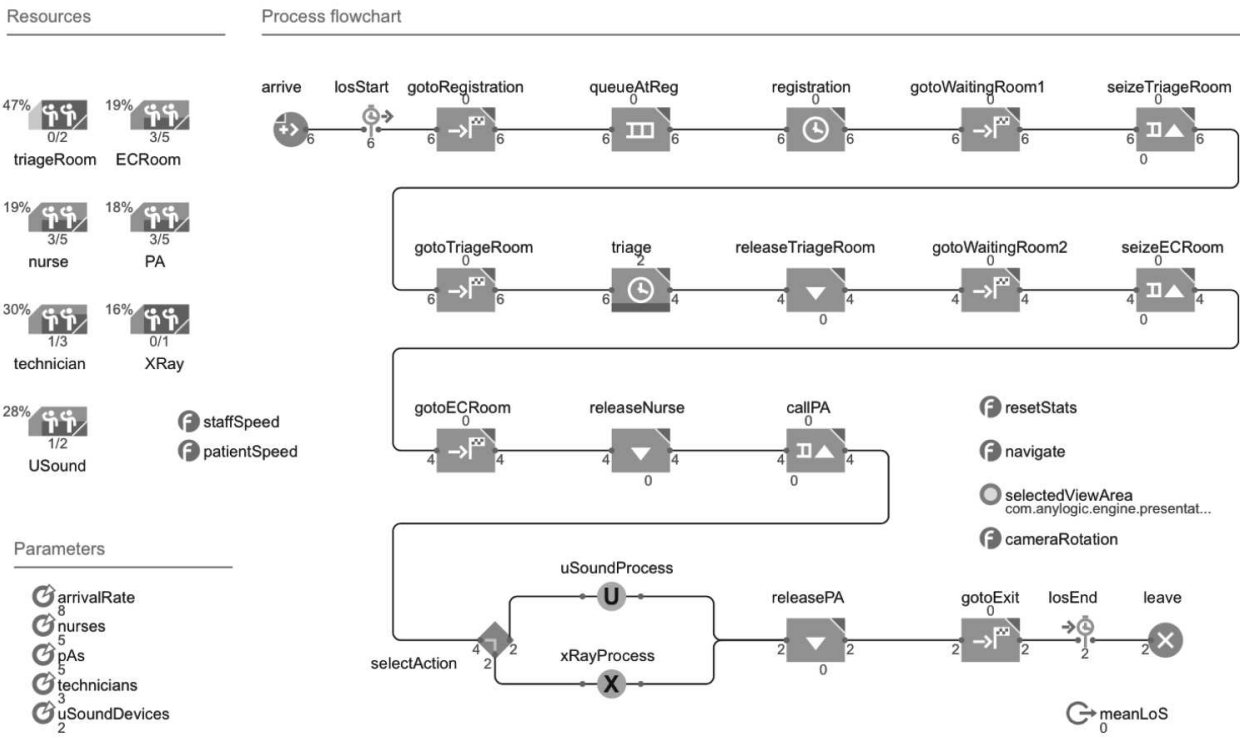

Figure 3. Emergency department discrete-event simulation model - logic (Anylogic, 2019) 


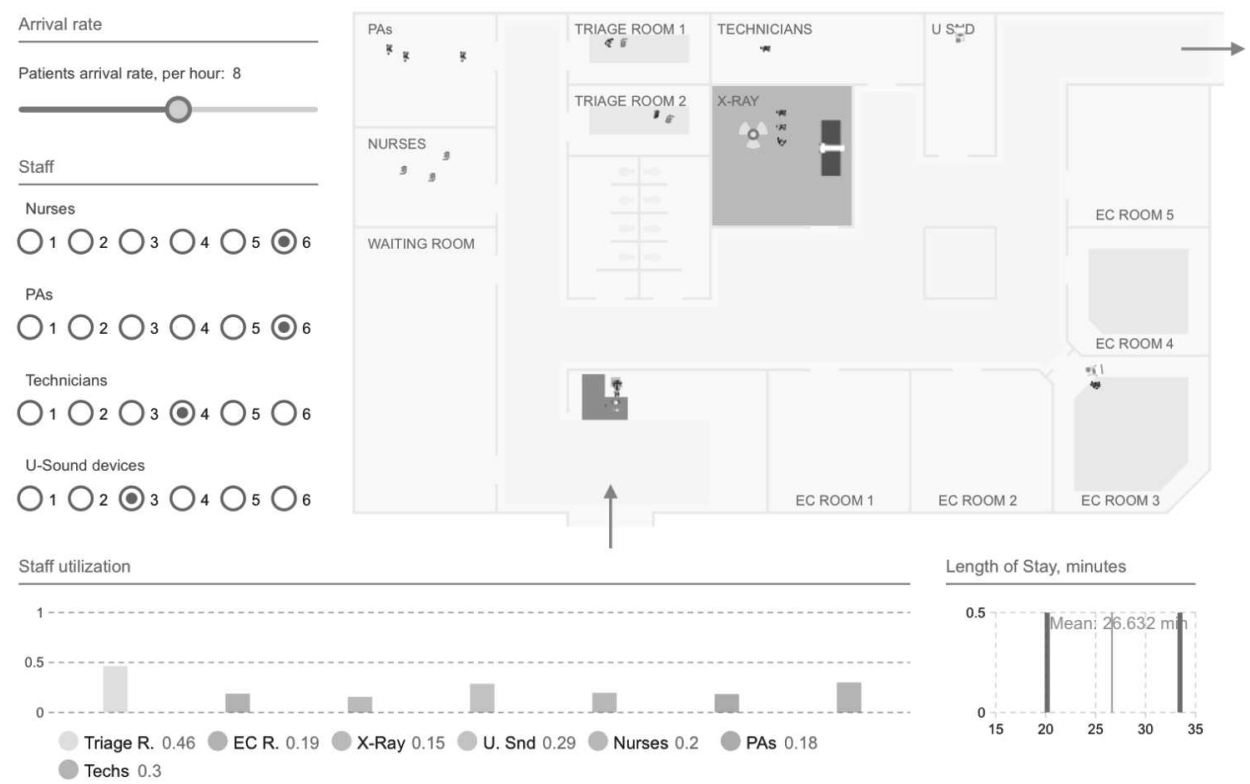

Figure 4. Emergency department discrete-event simulation model $-2 \mathrm{D}$ view (Anylogic, 2019)

\section{Conclusion}

The lean approach is not very common in Polish hospitals. There are some implementations, but they are rather fragmentary and do not apply to the whole process. This situation should change, as implementation of the lean approach would give much room for improvement of healthcare services. Healthcare process analysis could be supported by IT technology in different roles, for the following:

- Data acquisition;

- Data processing;

- Process analysis, forecasting, configuration (simulation).

A single reference model implemented by Minister of Health regulation would make it possible to achieve scalable effect for implementations of possible solutions in EDs.

For emergency departments, it is common to assume time-to-bed and length of stay as output parameters. Input data include resources, such as beds, equipment, cars, doctors, nurses, technicians, etc. The goal might consist in optimal allocation of cars and rescue bases, paramedics, doctors, nurses, and equipment as well as organization of care services, which enable the achievement of the required service level. 
The presented examples, even those simplistic in their nature, proved to have great potential for improvement and a significant impact of basic lean management tools on the effectiveness of healthcare services in an example Polish ED. It is worth noting that the presented example also presents further possibilities of improvement by enabling continuous flow whenever possible.

\section{R E F E R E N C E S}

Ahalt, V., Argon, N., Ziya, T., Strickler, S., \& Mehrotra, J. (2018). Comparison of Emergency Department Crowding Scores: A Discrete-event Simulation Approach. Health Care Management Science, 21(1), 144-155.

Antony, J., Sunder, M.V., Sreedharan, R., Chakraborty, A., \& Gunasekaran, A. (2019). A systematic review of Lean in healthcare: a global prospective. International Journal of Quality \& Reliability Management, 36(8), 13701391.

Anylogic (2019). Emergency Department. Retrieved from https://cloud.anylogic. com/model/6e194505-23a9-4029-8b3d-411b99d61451?mode=SETTINGS (14 $4^{\text {th }}$ Oct 2019).

Björnberg, A., \& Phang, A. Y. (2019). Euro Health Consumer Index 2018. Report. Health Consumer Powerhouse Ltd. Retrieved from https://healthpower house.com/media/EHCI-2018/EHCI-2018-report.pdf

Buczacki, A., Brzozowski, S., \& Timler, D. (2017). The map discussed during the conference 10th Polish Conference on Emergency Medicine. "Kopernik 2017", 17-19.11.2017.

Choi, D., Noh, Y., \& Rha, J. S. (2019). Work Pressure and Burnout Effects on Emergency Room Operations: A System Dynamics Simulation Approach. Service Business, 13(3), 433-456.

Freidson, E. (1972). The clinical mentality. In: Profession in Medicine. A Study of Sociology of Applied Knowledge, (pp. 158-184). New York: University of Chicago Press.

Gladysz, B., \& Buczacki, A. (2018). Wireless technologies for lean manufacturing A literature review. Management and Production Engineering Review, 9(4), $20-34$.

Graban, M. (2011). Lean Hospitals. Wrocław: ProdPublishing.

Imai, M. (2012). Gemba kaizen. A commonsense approach to a continuous improvement strategy. $2^{\text {nd }}$ ed. London: McGraw Hill.

Jimmerson, C. (2017). Value stream mapping for healthcare made easy. New York: Productivity Press.

Korkosz-Gębska, J., \& Gębski, J. (2018). Lean Healthcare Standards (in Polish: Standardy LeanOZ Mapowanie strumieni wartości w ochronie zdrowia). Hermanowski, T., Marciniak, S., Ryglewicz, D. (Eds). Warszawa: Polskie Towarzystwo Ekonomiki Zdrowia. 


\section{Aleksander Buczacki et al.}

Kovacevic, M., Jovicic, M., Djapan, M., \& Zivanovic-Macuzic, I. (2016). Lean thinking in healthcare: review of implementation results. International Journal for Quality Research, 10(1), 219-230.

Krafcik, J. (1998). Triumph of the Lean Production Systems. Sloan Management Review, Fall, 41-52.

Liker, J. (2004). The Toyota Way: 14 Management Principles from the World's Greatest Manufacturer. New York: McGraw-Hill.

Mielczarek, B. (2014). Simulation in management of health care systems (in Polish: Symulacja w zarzadzaniu systemami ochrony zdrowia). Warszawa: PWN.

Ohno, T. (1998). Toyota Production Systems: Beyond Large-Scale Production. Portland: Productivity Inc.

Radnor, Z.J., Holweg, M., \& Waring, J. (2012). Lean in healthcare: the unfilled promise? Social Science \& Medicine, 74(3), 364-371.

Ribeiro, R., Baungratz, E., Vaccaro, G., Schmitz, P. S., Fernandes, A., Colpani, V., \& Falavigna, M. (2016). PHS115 - Factors Influencing Door-To-Doctor Time In An Emergency Department: Discrete Event Simulation Model. Value in Health, 19(7), A624.

Rozporządzenie Ministra Zdrowia z dnia 27 czerwca 2019 r. w sprawie szpitalnego oddziału ratunkowego (2019). Dz.U. 2019 poz. 1213. Retrieved from http:// prawo.sejm.gov.pl/isap.nsf/DocDetails.xsp?id=WDU20190001213

Serwis Rzeczypospolitej Polskiej (2015). Krajowe Ramy Strategiczne. Policy Paper dla ochrony zdrowia na lata 2014-2020. Warszawa 2015. Retrieved from https://www.gov.pl/web/uw-warminsko-mazurski/krajowe-ramy-strategicz ne-policy-paper-dla-ochrony-zdrowia-na-lata-2014-2020

Serwis Rzeczypospolitej Polskiej (2019). Szpitalne oddziały ratunkowe. Retrieved from https://www.gov.pl/web/zdrowie/szpitalne-oddzialy-ratunkowe

Womack, J., \& Jones, D. (1996). Lean Thinking: Banish Waste and Create Wealth in Your Corporation. New York: Simon \& Schuster.

Womack, J., Jones, D., \& Roos, D. (1990). The Machine That Changed the World. New York: Free Press. 